\title{
STEM Education Using Emulation Software for Hydraulic Fluid Power Applications
}

\author{
Jesus Pagan MS* \\ Engineering Technology and Management Department, Ohio University, Athens, Ohio, USA \\ *Corresponding author: paganj@ohio.edu
}

\begin{abstract}
STEM education is an indispensable method to prepare students for future careers in engineering and manufacturing. Tools such as simulation software provide one way to explore and expand high school students' knowledge of hydraulic fluid power systems. Traditionally, hydraulic fluid power college courses have used a physical trainer equipped with cylinders, valves and hoses that demonstrate various circuits important to the understanding of fluid flow and system characteristics. Using Simumatik3D, a free downloadable emulation software developed in Sweden, a group of high school students were able to assemble an emulated environment where they can create new hydraulic circuits, allowing them to learn outside of the classroom and preparing them for classroom activities with a real physical trainer. The software system was selected as the platform to emulate the trainer because of the ease of use, its 3D environment and the potential for future expansion into electromechanical emulations that leverage the use of Programmable Logic Controllers (PLCs) and Robotics. Preliminary results of a small sample of high school students show that students were responsive to the Simumatik3D software and that the project met several best practices for engineering STEM applications.
\end{abstract}

Keywords: Emulation Software, Hydraulic Fluid Power, STEM

Cite This Article: Jesus Pagan MS, "STEM Education Using Emulation Software for Hydraulic Fluid Power Applications.” Journal of Business and Management Sciences, vol. 6, no. 3 (2018): 86-92. doi: 10.12691/jbms-6-3-4.

\section{Introduction}

According to the National Science Foundation [1], investments in science and engineering knowledge are critical to innovation and economic activity. A shortage of highly skilled workers trained in technology fields exists in the United States, yet motivating students to pursue STEM (science, technology, engineering, and math) fields has been a challenge. A lack of teacher training, limited access to equipment, and scarce funding have resulted in few engineering applications for K-12 students. According Rockland, et al. [2], one of the principle reasons that students do not pursue STEM majors in college is that they are not exposed to sufficient applications, particularly in engineering, during their secondary education. Interest in higher education's role in providing such applications has been growing.

Typically, K-12 STEM education does not include hydraulic fluid power applications, however, the concepts are easily transferrable to the high school level. Hydraulic Fluid Power is used in many applications from automotive to industrial operations. In most cases where high forces are required, hydraulic fluid power is the preferred choice. Also, in situations where electricity is not desired, then a hydraulic or pneumatic solution may be used. Construction equipment used for earth moving and mining operations as well as agricultural equipment used to harvest timber are good examples where hydraulic fluid power is used.
Attracting students to STEM education is important, yet the financial outlay can be high, especially when dealing with industrial components. Others have used fluid power to drive a robotic excavator arm as part of workshops to stimulate interest in STEM careers [3] as well as an introductory topic for middle school students where scientific principles and math concepts are taught in a hands-on experiential learning [4]. The following section examines a few industries and examples of the use of hydraulic fluid power to accomplish a variety of tasks followed by our approach to using emulation software to create interest in STEM at the high school level.

\subsection{Industrial Equipment}

Many fixed industrial machineries are based on hydraulic power to deliver the forces needed to forge, extrude or deform the raw materials into finished parts. For example, presses used for stamping operations as the one shown in Figure 1 are usually controlled by a Programmable Logic Controller (PLC) that manages a sequence of operations from feeding the parts into the press cavity via a conveyor belt to motion of the upper and lower dies and retrieval of the parts from the press. The lower die is usually fixed to the base of the machine while the upper die is attached to a hydraulic cylinder that moves up and down or sideways to deliver the deformation force required for the stamping operation. Other components are also controlled by the PLC such as light switches, light curtains, push buttons, relays, valves and safety switches to keep the operators safe. 


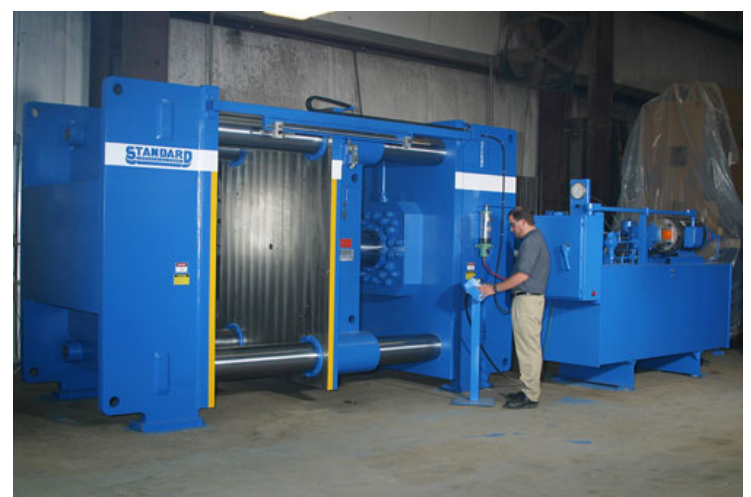

Figure 1. Horizontal 300 ton forming/150 ton stamping press [5]

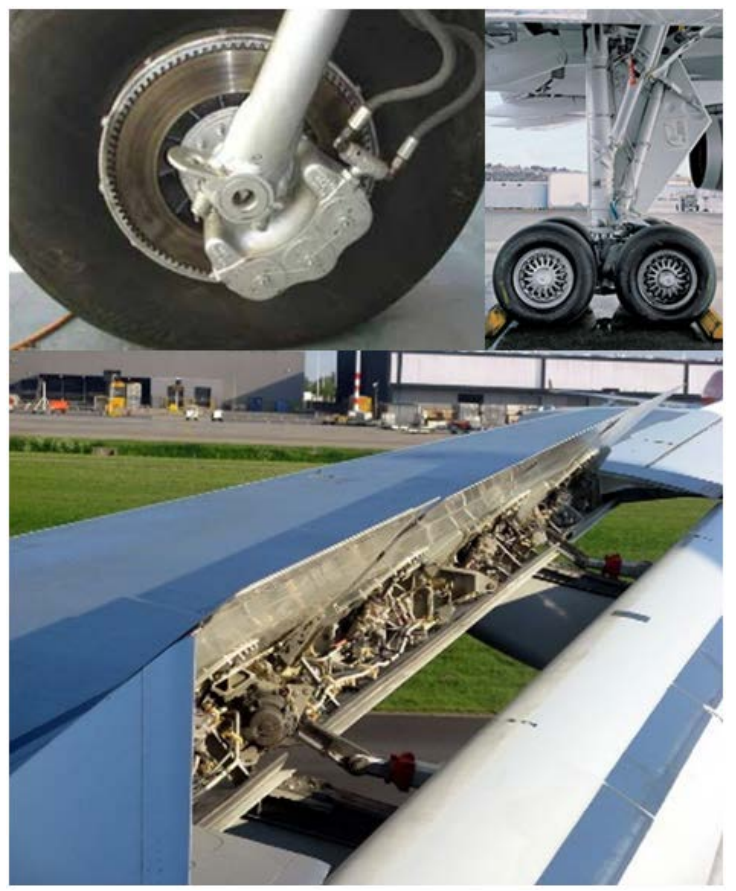

Figure 2. Airplane disk brake [6], landing gears [7], flaps and flight control surfaces [8]

\subsection{Aerospace Industry}

Aircraft systems, as shown in Figure 2, are powered and controlled via hydraulics such as brakes [6], landing gears [7], flaps and flight control surfaces [8]. These systems are ideal applications for hydraulics because of the amount of force required to stop a large airplane and the precision that can be delivered using hydraulic systems when compared to a pneumatic or electric system. The hydraulic systems in an aircraft are designed for redundancy and reliability, they are composed of multiple subsystems that include a pump or reservoir, accumulator, heat exchanger, filtering system and more [9].

From a basic hydraulic system (Figure 3) to more complex ones such as the one for a large commercial aircraft (Figure 4), the goal is the same to operate linear or rotary actuators using flow control valves such as selector valves, check valves, sequence valves, shuttle valves, pressure-controlled valves and manually controlled valves in order to operate the system or fly the aircraft.

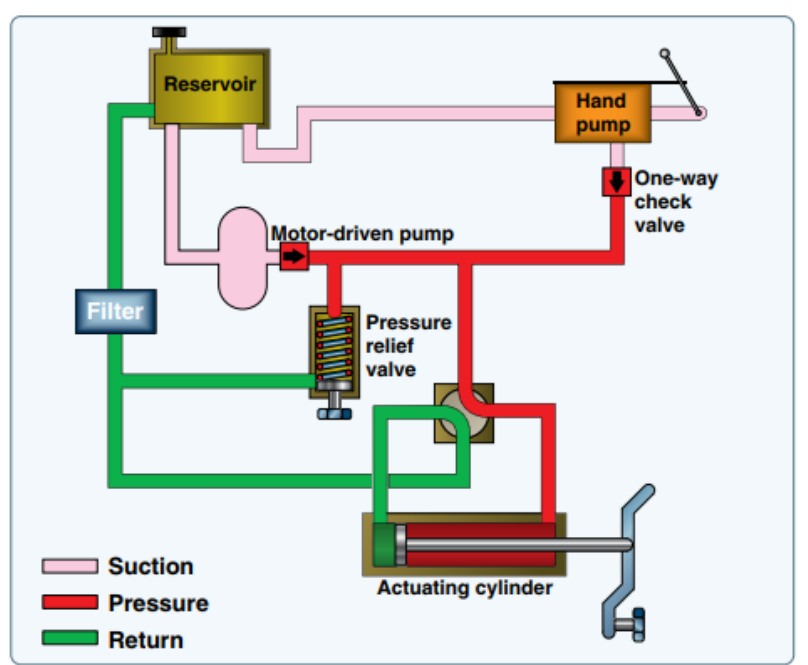

Figure 3. Example of a basic hydraulic system [9]

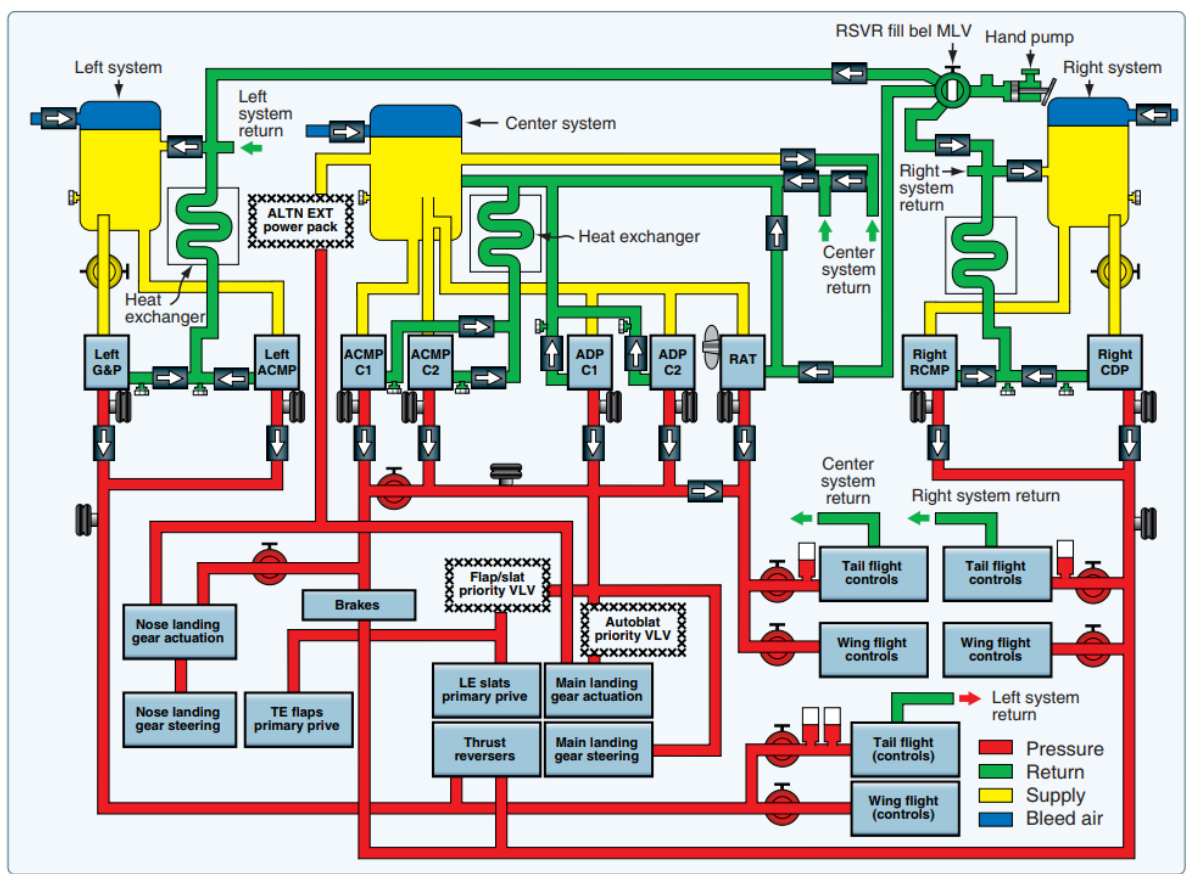

Figure 4. Example of a commercial aircraft hydraulic system [9] 


\subsection{Construction, Mining and Agriculture Industries}

Excavators, harvesters and material handlers shown in Figure 5 are examples of equipment that uses hydraulic power to manipulate, remove, crush and process various materials $[10,11,12]$. Usually operators of such equipment sit at a command station where they have complete view of their surroundings to drive the system using a joystick or levers that command linkages to move as they desire. These machines are already driven by an engine that powers the main drive system to go forward, backwards and side to side but in addition to that engine, a fluid powered reservoir with a pump is used to articulate the main arm holding a tool for the desired task.

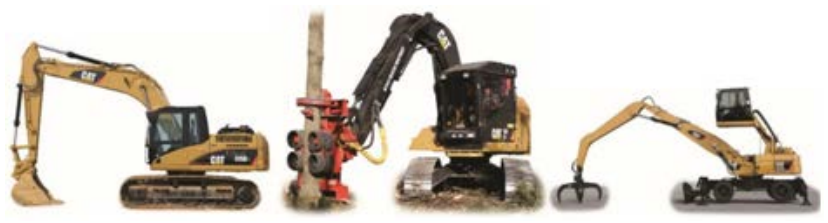

Figure 5. Hydraulic Excavator [10], Harvesters [11] and Material Handlers [12]

\section{Software and Hardware}

\subsection{Simumatik3D}

The Simumatik3D software can be downloaded for free and it was developed by Mikel Ayani and his team in 2014. It is licensed through Creative Commons (CC BY-NC-ND 4.0) and is based on Panda3D and Python. The software has been used to emulate industrial systems, test PLC code and interact with robotic systems typically before machines are built. Their development continues to transform the way Simumatik3D is used today [13].

At Ohio University, experimentation with the use of a Raspberry $\mathrm{Pi}$ to run CoDeSys software has been performed to drive the emulation of basic servo motor systems such as a 4 axes robotic manipulator. CoDeSys connects to Simumatik3D via OPC-UA server to create a link between the variables used for the emulation and CoDeSys. A sample video can be found at the following YouTube link [14] with other examples available at the Simumatik3D website.

In 2017, a team of researchers at Ohio University was awarded a grant from the National Fluid Power Association to develop educational resources for Hydraulic Power Systems. The project culminated with the development of a module within Simumatik3D for the emulation of the Parker Hydraulic Trainer described below in the application section.

\subsection{Parker Trainer and Components}

Although there are many Hydraulic Fluid Power Trainers in the market [15-20], shown in Figure 6, Ohio University uses Parker Hannifin's modular Hydraulic Trainer shown in Figure 7. The trainer is equipped with an aluminum backing panel for ease of component connectivity through modular plates. A power unit, hose assemblies, valves, double acting cylinders, pressure reducing valves, needle valves, pressure compensated flow control valves, tees, flow meters, pressure gauges, check valves, flow control valves with by-pass check and sequencing valves are among some of the components available with the trainer [21].

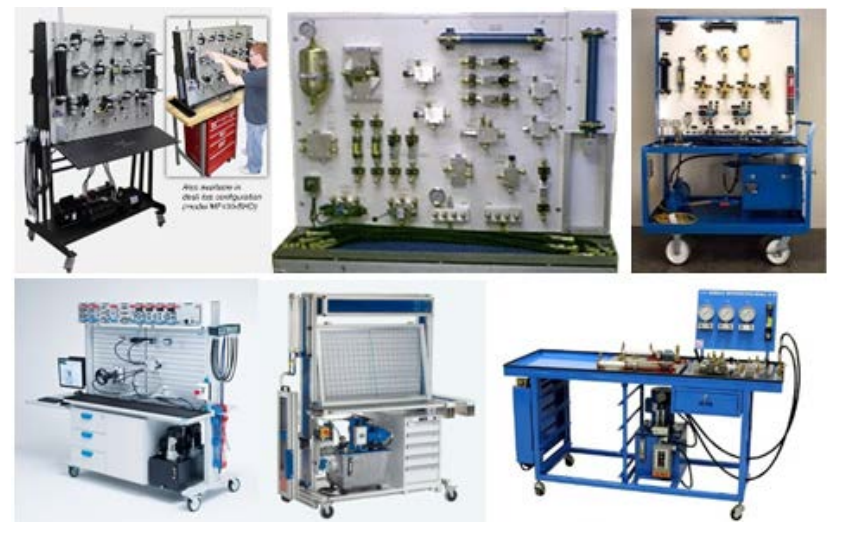

Figure 6. Hydraulic Fluid Power Industrial Trainers [15-20]

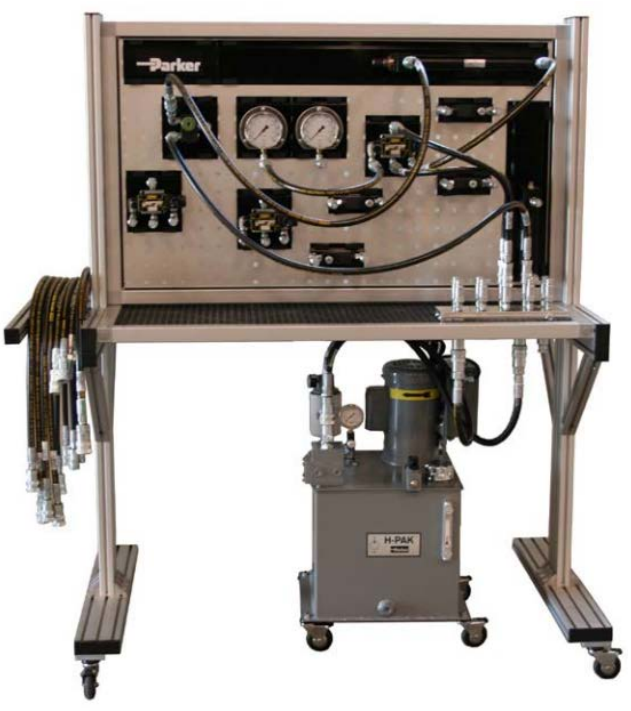

Figure 7. Parker Hydraulic Trainer [21].

\section{Application}

Although the module was first tested with college students, in this case study, emphasis is on exploring the experience with a small group of eleven local high school students who spent a few hours working on an application at Ohio University while visiting the Automation, Robotics and Controls Laboratory and the Parker Hannifin Hydraulics and Pneumatics Laboratory. This group of students have been exploring robotics and automation as part of a high school class with limited resources. Instructions (Simumatik3D - Introduction and use of the software) used by the students were part of the National Fluid Power Association module created for the Parker Hydraulic Trainer. The students followed the steps of creating a simple linear circuit and concluded the activity by using the software in a free form basis. The following describes a summary of the simulation steps and provides some insight information on the software. 


\subsection{Simulation Setup for a Basic Linear Circuit}

The Simumatik3D environment shown in Figure 8 consists of menu bar, icon bar, log window, object explorer, parameter panel and a main 2D/3D visualization window with other windows such as object library and output selection that can be open as needed. Onshape, a cloud based CAD software [22], was utilized to create all the models for the components that were imported into
Simumatik3D by saving the files in the COLLADA exchange format [23].

When creating a new simulation, a new project is created containing a Main Floor and Products objects that can be seeing in the Object Explorer window (Figure 9). The user then creates a new group from the Object Library (Figure 9) under the Main Floor before being able to import the parker_hyd_trainer into the environment with other objects becoming available in the Object Library subsequently.

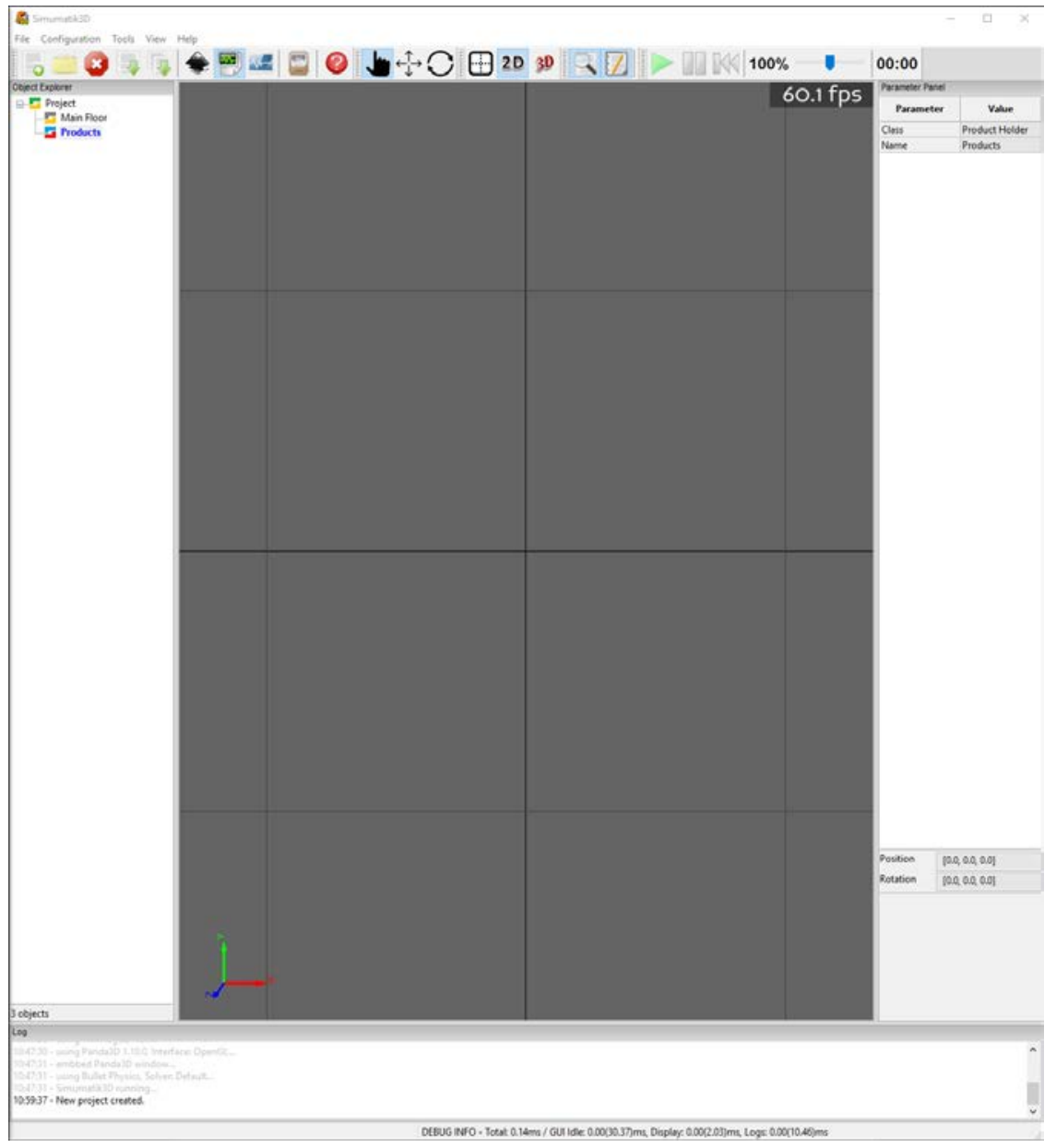

Figure 8. Simumatik3D environment

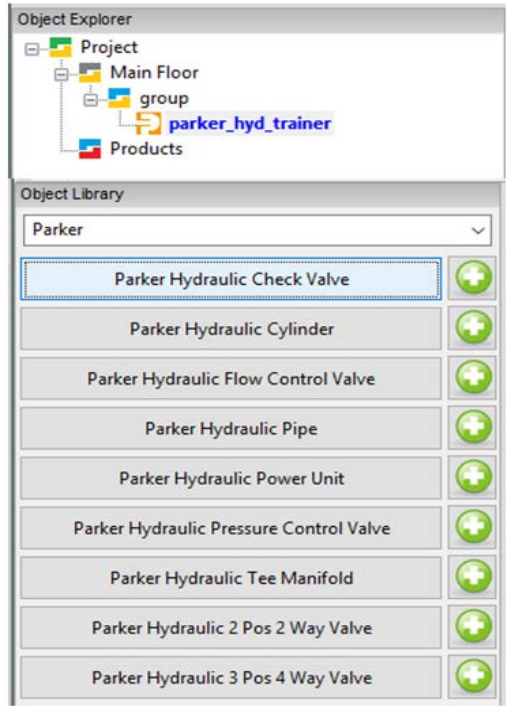

Figure 9. Object Explorer and Object Library
After adding other components (power unit, 3 positions 4-way valve, cylinder and piston) and rearranging them in the simulation window, shown in Figure 10, a point light was used to improve the visibility of the objects in the simulation and added shadows. The next step in the creation of the simulated circuit for extension and retraction of the piston was to connect the hoses (called Parker Hydraulic Pipe in the Objects Library) between the components. This is a critical component in the understanding of how circuits work and operate. It is important to note that all components come with preassigned ports, for example, the power unit has two ports with one called port $\mathrm{T}$ and the other port $\mathrm{P}$ with the valve having two additional ports named port $\mathrm{A}$ and port $\mathrm{B}$.

In this example, a valve with a tandem center is used to actuate a single-rod double acting cylinder powered by a hydraulic power unit. A basic schematic of the circuit is shown in Figure 11. Using the schematic as a guide, the user can make all the hose connections before playing the 
simulation to observe the fluid flow and verify the motion of the piston as it extends and retracts given the actuation of the valve into its three (left, home or right) positions. Figure 12 shows the extended and retracted positions of the piston with red hoses depicting the high-pressure fluid flow and white or grey hoses depicting no pressure. Also, blue hoses represent the active fluid flow throughout the system which are not shown in the example.

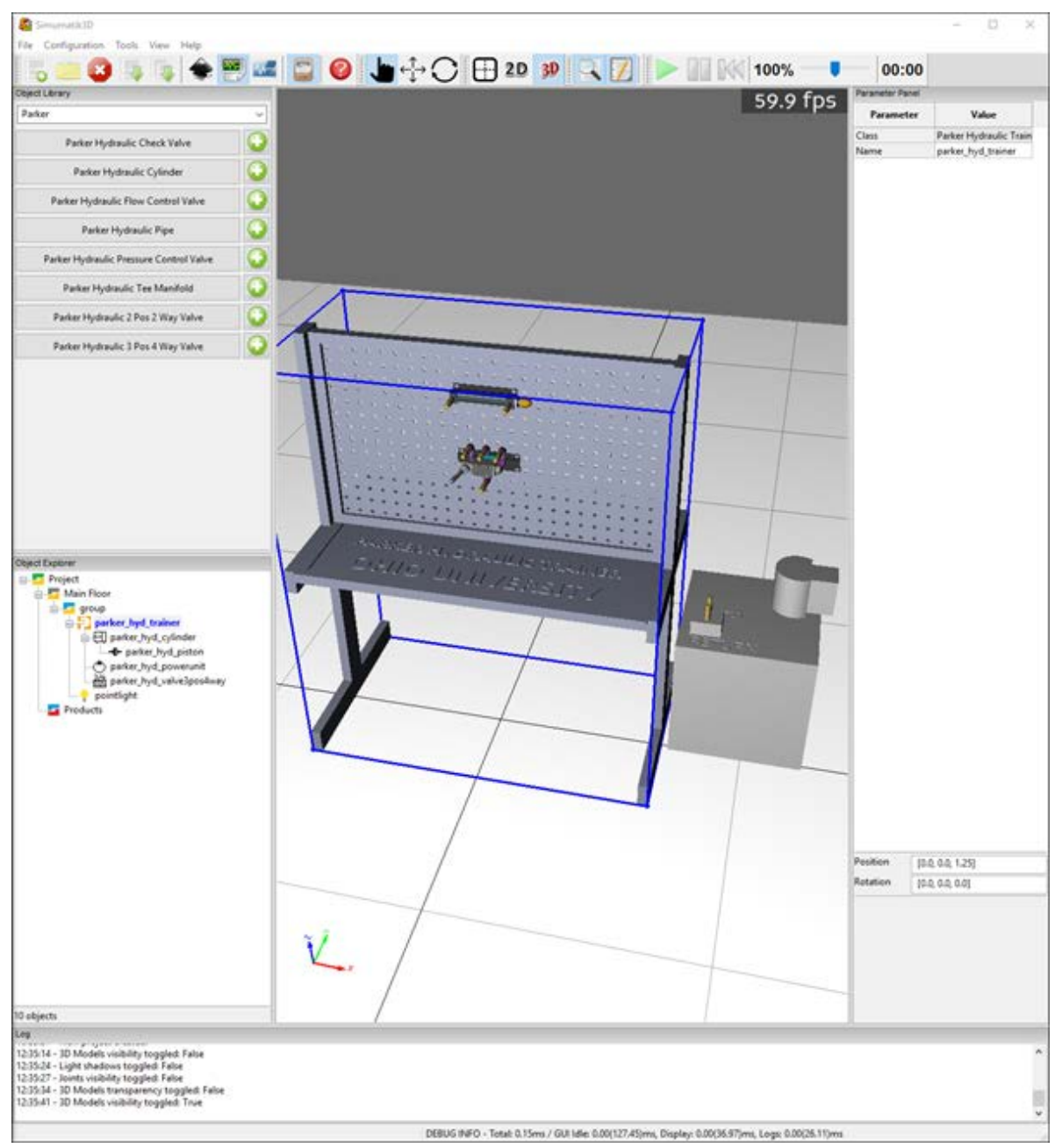

Figure 10. Trainer with power unit, valve, cylinder and piston before hoses are attached

Tandem Center

Single-rod, Double acting Cylinder

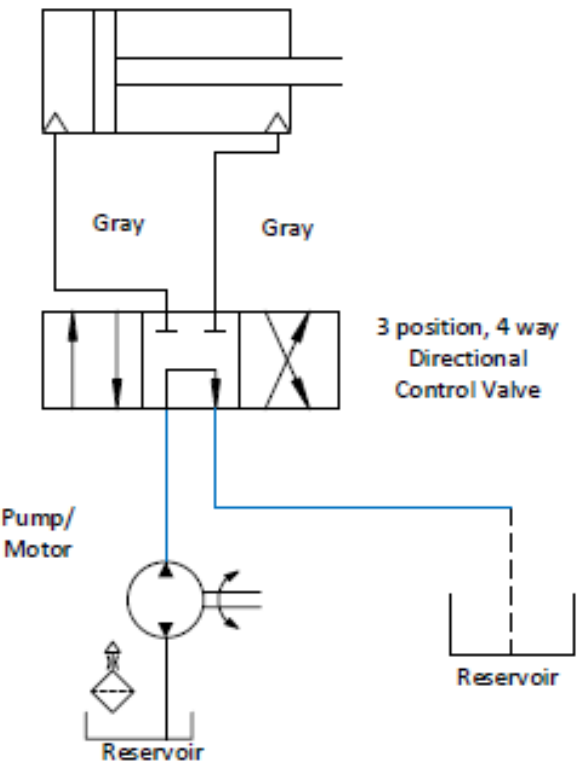

Figure 11. Basic Linear Circuit Schematic - Tandem Center

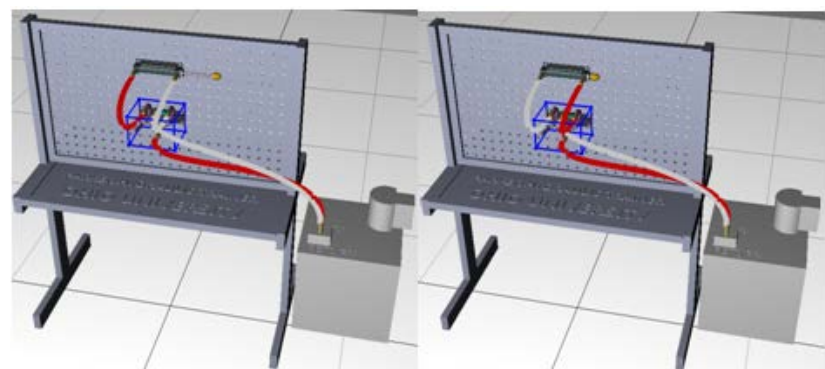

Figure 12. Position A - Extension and Position B - Retraction

\section{Discussion}

Many of the K-12 engineering applications center around robotics and computer programming, however many other types of applied projects are possible to increase enthusiasm for STEM fields. The Simumatik3D - Parker Hydraulic Trainer module provides a different type of case study for STEM education at the high school level. While it is still under investigation, initial work in this case study with the software revealed several ways that it is useful in K-12 STEM education. 


\subsection{Critical Thought}

Rockland, et al. [2] discuss best practices regarding incorporating engineering into K-12 education. Successful applications include specific examples that have real world relevance and lead to technological literacy that is relevant to the workforce. STEM applications are effective when they train students to "think like a scientist." This application allows students to test hypothesis, engage in trials, problem-solve, and see real world connections.

The specificity of this application allows for focused inquiry using active and in-depth learning opportunities which is a hallmark of STEM education best practices [24]. Many engineering projects focus on design but are not carried through completion. This project not only allows students to understand the design process associated with hydraulic fluid power, but it allows them to test their hypothesis through simulation in a $3 \mathrm{D}$ environment. The completion of a project from beginning to end enhances critical thought and problem solving associated with engineering. By creating a simple hydraulic circuit, the students could learn the concrete skill of using the software, see how the circuit operates in a simulate 3D space, and test other circuits for different applications.

\subsection{Ease of Use}

One of the constraints of engineering applications in STEM education is that they typically involve equipment, training, and expenses well beyond some of the schools funding. While instructors do need to be familiar with the software and engineering concepts behind hydraulic fluid power, the burden on the students and the system is light. The software is free which alleviates one of the most pressing constraints of engineering applications, the high cost of hardware and software.

The software provides a platform for the students to create hydraulic circuits anywhere without the need for a physical hydraulic trainer. Students are able to assemble an emulated environment where they can create new hydraulic circuits, allowing them to learn outside of the classroom and preparing them for classroom activities with a real physical trainer or like in this example, a visit to a local college or university that is equipped with these types of trainers. The software is simple, easy to use, and it provides a $2 \mathrm{D}$ as well as a $3 \mathrm{D}$ environment that emulates the real world. Students in this group found that the software was intuitive, and they began to understand complex concepts related to hydraulic fluid power in a short time. Instead of relying on a teacher, the ease of use of the program allowed them to draw conclusions about circuits, 3D modelling, and hydraulic fluid power.

\subsection{Potential for Other Applications}

Another best practice found in the STEM literature is that successful projects have a practical nature with possibilities for future applications [24]. While emphasis has been placed in the hydraulic fluid power for this case study, the software can be used in other STEM applications using Programmable Logic Controllers (PLCs), robotics, industrial automation, home automation and in other everyday control tasks. In order to draw out these future applications, the instructor can intentionally have student reflect on extensions of the project and also share examples of related work. For example, over 40 distinct circuits have been built for a college course at Ohio University. By understanding how the project can be generalized to other applications, the students see the value of the specific example and the potential for future expansion into electromechanical emulations that leverage the use of Programmable Logic Controllers (PLCs) and Robotics. This was the first time these students were exposed to the Simumatik3D software, but it was the third time they had visited the laboratories at Ohio University.

\subsection{Preliminary Student Response}

Although with a small group of high school students, the impact and interest in STEM education of the student before and after being exposed to the use of the modular hydraulic power trainer was measured through a short questionnaire with five questions. The students were given the questionnaire before and after to gauge their interest in STEM education while trying to meet three basic learning outcomes for the activity.

- Understand the function of a reservoir or power unit in a hydraulic system.

- Understand how a valve works to operate a linear or rotary actuator.

- Understand the operation of a linear circuit to control the cylinder's piston extension and retraction.

The activity developed for the students was an exposure to hydraulic power systems using the emulation module to create the simple hydraulic circuit described above and then the students could explore the software to see what other circuits they could create.

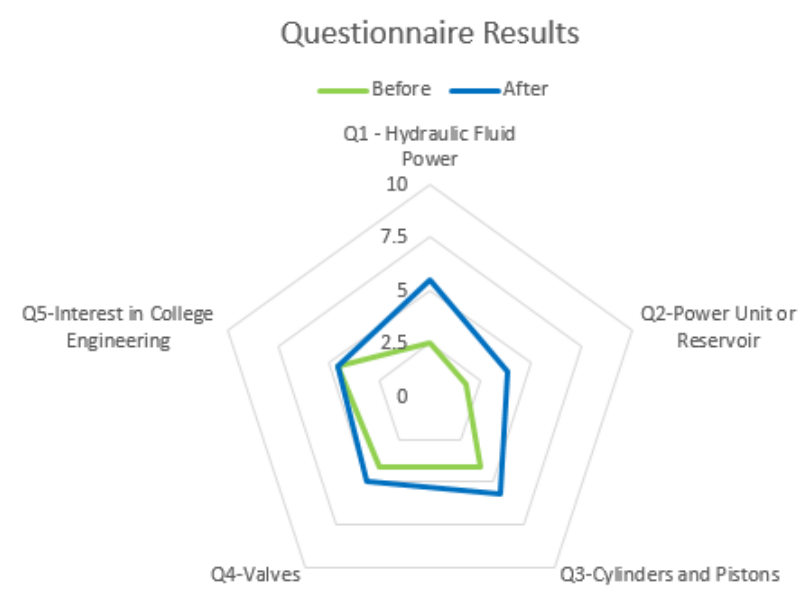

Figure 13. Chart of questionnaire results

After the interaction with this small group, the plan is to expand the exposure to the software to other high school groups and continue to measure the impact the software could have in STEM education for a larger population of students. Also, by providing training seminars, continued education units or continued education credits to high school teachers may facilitate the implementation of the software in their curriculum. The software is available for a free download from the Simumatik3D website at www.simumatik.com and access to the instructions will be made available soon. 
The questionnaire conducted with the small group of high school students revealed that the most of them had no idea or little knowledge about hydraulic fluid power(Q1). Their answers were also similar when asking about specifics such as the basic learning outcomes of understanding about a power unit(Q2), cylinders and pistons(Q3), and valves(Q4). Students consistently reported increased understanding of engineering concept. As shown in Figure 13, in each curricular area, student knowledge jumped from the level of "no or little" knowledge to "moderate" knowledge by the end of the session.

When asked about their interest in studying engineering in college(Q5), their answers did not change. Since the activity was conducted at the end of the school year and students attending the learning activity were mostly seniors, it is conceivable that they have already made up their minds of what careers they want to pursue. In addition, the duration of this project was short and introductory. Allowing students to work on these concepts over a longer period may have a bigger impact on future plans. It is difficult to make any clear conclusions as the number of students surveyed was small and future surveys with a larger sample size can determine the impact on learning.

\section{Conclusion}

This paper provides a case study of how STEM applications can be expanded to use emulation software for hydraulic fluid power applications. The simulated hydraulic fluid power project has a number of features that are particularly appealing for K-12 STEM applications. The software is easy to use and is free to download, thereby reducing any barriers to equipment access. The type of activities that students engage in with the software help them develop critical thinking skills necessary for engineers. The concepts are generalizable and transferrable to other applications. A preliminary survey of high school students who went through the study learning the software shows evidence that exposure to this project increased their knowledge in all curricular content areas. The students will continue working with the software and future interactions with the software should have a positive influence in the students' knowledge and interest in hydraulic fluid power as well as in STEM careers.

\section{Acknowledgements}

The author wishes to thank the National Fluid Power Association for their funding support and the collaborators in the grant, Dr. Yuqiu You and Dr. William Reeves for their contributions towards this project. Also, special thanks to Mikel Ayani, the creator of Simumatik3D, for his support and continued efforts to develop great educational resources.

\section{References}

[1] "Science and Engineering Indicators," National Science Foundation, [Online]. Available:

https://www.nsf.gov/statistics/2018/nsb20181/. [Accessed 254 2018].
[2] R. B. D. C. J. B.-A. L. H. L. a. K. H. Rockland, "Advancing the "E" in K-12 STEM Education," Journal of Technology Studies, vol. 36, no. 1, pp. pp. 53-54, 2010.

[3] D. J. M. Garcia, "Using fluid power workshops to increase STEM interest in K-12 students," American Society for Engineering Education, no. 121st ASEE Annual Conference and Exposition, 2014.

[4] S. Rogers, "Using Fluid Power in the Middle School Classroom," Technology and Engineering teacher, pp. 17-22, March 2013.

[5] 303 2018. [Online]. Available: http://www.standard-industrial.com/custom-manufacturedhorizontal-press.html.

[6] [Online]. Available: http://okigihan.blogspot.com/p/aircraft-brakes_9081.html. [Accessed 313 2018].

[7] [Online]. Available: http://www.boeing.com/commercial/aeromagazine/articles/qtr_02 _09/article_03_1.html. [Accessed 313 2018].

[8] [Online]. Available: https://commons.wikimedia.org/wiki/File:Lift_dumperinnerworki ngsa320.jpg. [Accessed 313 2018].

[9] U. D. o. T. F. A. Administration, Aviation Maintenance Technician Handbook-Airframe, Volume 2, FAA-H-8083-3I, 2012.

[10] [Online]. Available: http://www.empire-cat.com/new_and_used_equipment/new_ equipment/popular_equipment/cat_hydraulic_excavators.aspx. [Accessed 303 2018].

[11] [Online]. Available: http://www.empire-cat.com/new_and_used_equipment/new_ equipment/popular_equipment/cat_harvesters.aspx. [Accessed 303 2018].

[12] [Online]. Available: http://www.empire-cat.com/new_and_used_equipment/new_ equipment/popular_equipment/wheel_material_handlers.aspx. [Accessed 303 2018].

[13] [Online]. Available: https://simumatik.com/index.php/about/about-us. [Accessed 303 2018].

[14] [Online]. Available: https://www.youtube.com/watch?list=PLlaeyxqFKfKOusGn_dh_ L19g0w6hChgDf\&time_continue=18\&v=ucA8HL1Fzy4 . [Accessed 313 2018].

[15] [Online]. Available: http://www.fpti.org/simulators_hydraulic_MF100B.php. [Accessed 313 2018].

[16] [Online]. Available: http://www.tctrainers.com/basic_hydraulic_trainer.html. [Accessed 303 2018].

[17] [Online]. Available: http://www.futuretekinc.com/product/plc-model-9501/. [Accessed 313 2018].

[18] [Online]. Available: http://www.festo-didactic.com/int-en/learning-systems/equipmentsets/hydraulics/training-packages/equipment-set-tp-800-mobilehydraulics-from-basic-principles-to-mobilemachine.htm?fbid=aW50LmVuLjU1Ny4xNy4xOC41NTYuNzYz Nw. [Accessed 313 2018].

[19] [Online]. Available: https://dc-us.resource.bosch.com/media/us/training_2/documents_ 36/ds4_hydraulic_training_system.pdf. [Accessed 313 2018].

[20] [Online]. Available: https://amatrol.com/coursepage/15793-2/. [Accessed 313 2018].

[21] [Online]. Available: https://www.parker.com/literature/Training/Hydraulics\%20Trainin g/PSK_HYD_LR_11Nov10.pdf. [Accessed 313 2018].

[22] [Online]. Available: https://www.onshape.com/. [Accessed 313 2018].

[23] [Online]. Available: https://www.khronos.org/collada/. [Accessed 313 2018].

[24] R. a. D. J. Custer, "The nature and status of STEM professional development: Effective practices for secondary level engineering education," Research in Engineering and Technical Education, National Center for Engineering and Technology Education, 200901-01. 